\title{
A particle swarm approach to solve environmental/economic dispatch problem
}

\begin{tabular}{l}
\hline A R T I C L E I N F O \\
\hline Article history: \\
Received 30 April 2010 \\
Received in revised form \\
2 June 2010 \\
Accepted 2 June 2010 \\
Available online 3 June 2010 \\
\hline Keywords: \\
Meta-heuristic \\
Particle swarm optimization \\
Economic dispatch \\
Emission controlled \\
Unit commitment \\
Multi-objective optimization
\end{tabular}

Yee Ming Chen ${ }^{\mathrm{a}^{*}}$ and Wen-Shiang Wang ${ }^{\mathrm{b}}$

${ }^{a}$ Department of Industrial Engineering,Yuan Ze University, Taiwan

${ }^{b}$ Department of Marketing and Logistics, Hsin Sheng College of Medical Care and Management, Taiwan A B S T R A C T

\begin{abstract}
This paper proposes a particle swarm optimization (PSO) algorithm to solve various types of economic dispatch (ED) problems in power systems such as, environmental/economic dispatch (EED) and multi-area environmental/economic dispatch. The proposed model considers the environmental impact to achieve the minimization of fuel costs and pollutant emissions, simultaneously. The EED problem is further extended to dispatch the power among different areas to aid emission allowance trading. The performance of the proposed PSO is compared with conventional method and genetic algorithm. The results clearly show that the proposed algorithms give global optimum solution compared to the other methods. The results obtained also show that the proposed PSO algorithms can provide comparable dispatch solutions with reduced computation time for all types of ED problems.
\end{abstract}

(C) 2010 Growing Science Ltd. All rights reserved.

\section{Introduction}

The basic objective of economic dispatch (ED) of electric power generation is to schedule the committed generating unit outputs to meet the load demand at minimum operating cost subject to system equality and inequality constraints. However, with the increasing public awareness of the environment protection and the passage of the Clear Air Act Amendments of 1990, we need to reduce the pollution and atmospheric emissions of the thermal power plants using newly designed facilities. Several available options to reduce the emissions are (1) switching to low sulphur content coal which depends mainly on the availability and price of such fuel; (2) the installation of scrubbers, which requires time to design, testing and installation with a large capital investment; (3) dispatch of power generation to minimize emissions instead of or as a supplement to the usual cost objective of economic dispatch. The first two options require installation of new equipment and/or modification of the existing ones involve considerable capital outlay and, hence, they can be considered as long-term options. The third option involves only minor modifications on dispatching programs for implementing environmental/economic dispatching (EED). The implementation of an EED is relatively low cost method to reduce emission without violating the constraints. The harmful ecological effect caused by the emission of gaseous pollution can be reduced by adequate distribution of load between the plants of power system where several constraints are also involved. This leads to increase in the operating cost of the plants. Environmental/economic dispatch is a multi-objective problem with conflicting objectives such as pollution minimization which is in conflict with minimization of cost of generation. Many researchers have considered emissions either in the objective function or treated them as additional constraints. During the past two decades, there have

\footnotetext{
* Corresponding author. Tel: 886-3-4638800 ext 2515, Fax: 886-3-4638907

E-mail addresses: chenyeeming@saturn.yzu.edu.tw (Y. M. Chen) 
been some efforts to propose new methods for this multi-objective problem (Palanichamy and Srikrishna, 1991; Dhillon et al., 1993) and an excellent summary on the various techniques and emission models to reduce emissions into atmosphere was presented by Talaq et. al. (1994). An EED problem normally has several objectives which could be converted into a single objective problem by linear combination of different objectives as a weighted sum (Dhillon et al. 1993; Farag et al., 1995; Chang et al., 1995). Unfortunately, this requires multiple runs as many times as the number of desired Pareto-optimal solutions and we cannot guarantee to reach to uniform Pareto-optimal solutions. For example, when this approach is applied to a multi-objective problem that has a concave tradeoff surface, it converges to two extreme optimums without showing any tradeoff information between the objectives. Evolutionary Algorithms (EAs), on the other hand, are particularly suited for multiobjective problems by maintaining a population of design candidates and using a fitness assignment method based on the Pareto-optimality concept. Because evolutionary algorithms deal with a group of candidate solutions, it seems natural to use this kind of procedure to find a group of Pareto optimal solutions, simultaneously. One possible alternative to solve the EED problem is to use evolutionary algorithms. Recently, there have been some interest to use the EA based optimizations techniques (Abido, 2003; Sudhakaran \& Slochanal, 2004; Yalcinoz \& Altun, 2005) and the main focus was to use genetic algorithms. On the other hand, particle swarm optimization (PSO) algorithm has been successfully used to solve ED problem (Wang \& Singh, 2006). Essentially, PSO is similar to EA, while defined in a social context rather than modeling the biological perspective of genetic algorithms. Similar to other EAs, it works with a population referred to as a swarm and each individual is called a particle. Each particle "flies" over the search space to look for promising regions according to its own experiences. Consequently, the sharing of social information takes place and individuals profit from the discoveries and the previous experiences of all other particles during the search. As with other EAs, PSO has the ability to search over a wide landscape around the better solutions for the EED problem. In addition, PSO algorithm has other advantages such as robustness, efficiency, as well as suitability for parallel computing. Therefore, PSO algorithm is a unique and attractive approach for real-world design optimization in EED problem.

This paper focuses on single pollutant, nitrogen oxides $\left(\mathrm{NO}_{\mathrm{x}}\right)$, because its control is a significant issue at the global level and it uses PSO algorithm to solve EED problems. A price penalty factor $(h)$ is defined which blends the emission costs with the fuel costs which avoids the use of two classes of dispatching and need to switch over between them. The familiar quadratic form of objective functions are used which gives the optimal dispatch, directly. Another factor called power balance penalty factor $(p f)$ is introduced to penalize the violation of constraints and forces the unconstrained optimal solution towards the feasible region. The capacity limits (lower and upper) of plants are treated as the operating constraints and the total generation which is a function of load plus transmission losses is considered as demand constraint. In this paper, we further extend the concept of EED into the multiarea environmental/economic dispatch (MEED), where power is dispatched within multiple areas (or countries). The MEED problem which determines the "optimal" development of the interconnections, taking into account the controlling emission limits for each area, with the possible resources to flexibility mechanism such as emission trading. The MEED is proposed by also minimizing the operational costs and pollutant emissions using PSO algorithm, simultaneously. The remainder of the paper is organized as follows: In Section 2, the EED and MEED problems are formulated. The proposed PSO algorithm is discussed in Section 3. Simulation results and comparison analysis are given in Section 4. Finally, conclusions are drawn and future research directions are suggested.

\section{Problem Description}

The problem formulation for two types of ED problems are first described in this section. The environmental/economic dispatch (EED) is an extension of ED problem where environmental issues have also been considered. The EED problem is further extended to economic dispatch the power among multi-area environmental/economic dispatch (MEED) by minimizing the operational costs and pollutant emissions, simultaneously where power is dispatched within multiple areas. 


\subsection{Formulation of EED problem}

The environmental/economic dispatch (EED) involves the simultaneous optimization of fuel cost, emission objectives which are conflicting ones and it is formulated as follows. The economic dispatch and emission dispatch are considerably different. The economic dispatch reduces the total fuel cost of the system at an increased rate of $\mathrm{NO}_{\mathrm{x}}$. On the other hand, emission dispatch reduces the total emission from the system by an increase in the operating cost of the system. Therefore, it is necessary to look for an operating point which strikes a balance between cost and emission which is achieved by environmental/economic dispatching. In the case, the EED can be formulated as:

$\min \left(F^{1}, F^{2}\right)=F^{1}+h \cdot F^{2}=\sum_{i=1}^{n}\left(a_{i} \cdot P_{i}^{2}+b_{i} \cdot P_{i}+c_{i}\right)+h \cdot \sum_{i=1}^{n}\left(\alpha_{i} \cdot P_{i}^{2}+\beta_{i} \cdot P_{i}+\gamma_{i}\right)$

subject to

$\sum_{i=1}^{n} P_{i}-P_{\text {demand }}-P_{\text {loss }}=0$,

$P_{i}^{\min } \leq P_{i} \leq P_{i}^{\max }$,

where $F^{1}$ is the expected fuel cost, $a_{i}, b_{i}, c_{i}$ and $c_{i}$ are the fuel cost coefficients. $F^{2}$ is the expected $\mathrm{NO}_{\mathrm{x}}$ emission (as an example only $\mathrm{NO}_{\mathrm{x}}$ reduction is considered) which may be related the cost curve through the emission rate per MBtu. Also, $\alpha_{i}, \beta_{i}$ and $r_{i}$ are the emission coefficients of generator $i$ and $h$ is the price penalty factor which blends the emission cost with the fuel costs. The objective function is resulted by adding the cost of fuels and emission. The first constraint is associated with demand and the second constraint represents the capacity limitations. $P_{\text {demand }}$ is the total power demand, $P_{i}^{\min }, P_{i}^{\max }$ are minimum and maximum generating capacity of unit $i$, respectively. $P_{\text {loss }}$ is transmissions losses of the power flow on lines. A common approach to model transmissions losses in the system is to use Kron's approximated loss formula through B-coefficients (Dhillon et.al, 2002; Huang , 2003) which is as follows,

$$
P_{\text {loss }}=\sum_{i=1}^{n} \sum_{j=1}^{n} P_{i} \cdot B_{i j} \cdot P_{j}
$$

where $B_{i j}$ is the elements of loss coefficient matrix $B_{m n}$ on transmission lines.

To achieve both objectives in a single dispatch we use combined economic and emission dispatch technique where the problem is to find the price penalty factor. In fact, it is very difficult that the penalty values are suitably selected. If the penalty values are high, the minimization algorithms usually get trapped in local minimum. On the other hand, if penalty values are low, they can hardly detect feasible optimal solutions. The penalty values are dynamically modified according to equality and inequality constraints. The value of $h$, is determined from the heuristic method given in (Palanichamy \& Srikrishna, 1991) with the following steps,

1. Evaluate the average cost of each generator at its maximum output; i.e.,

$$
\frac{F^{1}\left(P_{i}^{\max }\right)}{\left(P_{i}^{\max }\right)} \text {...Rs / MWhr }
$$

Evaluate the average $\mathrm{NO}_{\mathrm{x}}$ emission of each generator at its maximum output; i.e.,

$$
\frac{F^{2}\left(P_{i}^{\max }\right)}{\left(P_{i}^{\max }\right)} \ldots \mathrm{kg} / \mathrm{MWhr}
$$


2. Divide the average cost of each generator by its average NOx emission; i.e.,

$$
\frac{\text { Equ.(5) }}{\text { Equ.(6) }}=\frac{F^{1}\left(P_{i}^{\max }\right)}{F^{2}\left(P_{i}^{\max }\right)}=h_{i} \ldots R s / \mathrm{kg} \quad i=1,2, \ldots, n
$$

3. Arrange the values of price penalty factor $\left(h_{i}, i=1, \cdots, n\right)$ in ascending order

4. Add the maximum capacity of each unit $\left(P_{i}^{\max }\right)$ one at a time, starting from the smallest $h_{i}$ unit until $\sum_{i=1}^{n} P_{i}^{\max } \geq P_{\text {demand }}$

5. At this stage, $h_{i}$ associated with the last generator in the process is the price penalty factor $h$ (Rs/kg) for the given power demand

The procedure gives the approximate value of price penalty factor computation for the corresponding power demand. Hence, a heuristic price penalty factor is introduced in this paper to give the exact value for the particular load demand.

\subsection{Formulation of MEED problem}

The objective of multi-area dispatch is to determine the generation levels and the interchange power between areas that minimize both fuel and emission costs while satisfying a set of constraints as:

$$
\min \sum_{m=1}^{M}\left[F_{m}^{1}, F_{m}^{2}\right]=\sum_{m=1}^{M} \sum_{i=1}^{n}\left(a_{m i} \cdot P_{m i}^{2}+b_{m i} \cdot P_{m i}+c_{m i}\right)+\sum_{m=1}^{M}\left[h_{m} \cdot \sum_{i=1}^{n}\left(\alpha_{m i} \cdot P_{m i}^{2}+\beta_{m i} \cdot P_{m i}+\gamma_{m i}\right)\right],
$$

where $n$ is the number of on-line generators for the area $m$ in a $M$ area system, $a_{m i}, b_{m i}$ and $c_{m i}$ are the fuel cost coefficients and $\alpha_{m i}, \beta_{m i}$ and $\gamma_{m i}$ are the coefficients of emission of generators $i$, respectively. $P_{m i}$ is the power output generator $i$ and $h_{m}$ is the price penalty factor in area $m$. The constraints involved with the problem formulation are as follows,

(a) Area demand balance

In area $m$, the total power generation must cover the local area demand $P_{\text {demand, } m}$ and the transmission loss $P_{\text {loss }, m}$ with the consideration of imported and exported power. This relationship can be expressed as:

$$
\sum_{i=1}^{n} P_{m i}-\sum_{\substack{m=1 \\ m \neq k}}^{M}\left[t_{m k}-\left(1-\rho_{k m}\right) \cdot t_{k m}\right]-P_{\text {demand }, m}-P_{l o s s, m}=0
$$

(b) Area generations capacity:

$$
P_{m i}^{\min } \leq P_{m i} \leq P_{m i}^{\max }
$$

(c) Tie line capacity limits:

$$
t_{k m}^{\min } \leq t_{k m} \leq t_{k m}^{\max }
$$

where $t_{k m}, \rho_{\mathrm{km}}$ are the economic tie transfer power and the tie line transfer loss ratio from area $k$ to area $m$. Also, $P_{\text {demand, } m}$ and $P_{\text {loss, } m}$ are the local demand and transmission loss for area $m, t_{k m}^{\min }$ and $t_{k m}^{\max }$ are the tie line minimum and maximum capacity limits from area $k$ to area $m$ and finally $P_{m i}^{\min }$ and $P_{m i}^{\max }$ are the minimum and the maximum power output of generator $i$ in area $m$. 


\section{A PSO for EED/MEED}

The practical EED/MEED problems are represented as a nonlinear programming problem with equality and inequality constraints where the optimal solution cannot be found very easily. Therefore, we use PSO as a meta-heuristic approach to find the near optimal solution which is a member of swarm intelligence methods (Kennedy \& Eberhart, 2001). Kennedy specifies PSO as a simulation of social behavior, and it was initially introduced as an optimization method in 1995 (Kennedy \& Eberhart, 1995).

\subsection{PSO Algorithm}

The PSO can be easily implemented and it is computationally efficient when compared with mathematical algorithm and other heuristic optimization techniques. PSO has particles or population of individuals to move through the $d$-dimensional search space and each individual maintains a speed that acts as an operator to obtain a new set of individuals. The population of candidate solutions in PSO technique is moved through the search space updating the positions according to velocity factors. Its basic principal is based on the idea that each solution can be represented as a particle in a swarm and each particle has a position and velocity vector. Each position coordinate represents a parameter value. In a physical $d$-dimensional search space, the position and velocity of individual $i$ are represented as the vectors $P_{i}=\left(p_{i 1}, \cdots, p_{i d}\right)$ and $V_{i}=\left(v_{i 1}, \cdots, v_{i d}\right)$, respectively. Let Pbest $_{i}=\left(p_{i 1}^{\text {Pbest }}, \cdots, p_{i d}^{\text {Pbest }}\right)$, and Gbest $_{i}=\left(p_{i 1}^{\text {Gbest }}, \cdots, p_{i d}^{\text {Gbest }}\right)$ be the best location of individual $i$ and its neighbors' best location, respectively. Using the information, the updated velocity of individual $i$ is modified under the following equation in the PSO method:

$$
\begin{aligned}
V_{i}^{k+1}(t+1)= & w \times V_{i}^{k}(t)+c_{1} \times \operatorname{rand}() \times\left(\text { Pbest }_{i}^{k}(t)-P_{i}^{k}(t)\right) \\
& +c_{2} \times \operatorname{rand}() \times\left(\operatorname{Gbest}_{i}^{k}(t)-P_{i}^{k}(t)\right) \\
P_{i}^{k+1}(t+1)= & P_{i}^{k}(t)+V_{i}^{k+1}(t+1)
\end{aligned}
$$

where $w$ is the inertia weighting factor, $c_{1}$ and $c_{2}$ are weight factors; and rand() is random number between 0 and 1 . As originally developed, $w$ often decreases linearly from about 0.9 to 0.4 during each iteration. A good selection of the inertia weighting factor provides a balance between global and local exploration and exploitation, and results in fewer iterations on average to find a sufficiently optimal solution. Its value is set according to the following equation (Shi \& Eberhart, 1998; Abido, 2002):

$w=w_{\max }-\frac{w_{\max }-w_{\min }}{\text { iter }_{\max }} \times$ iter,

where iter $_{\max }$ is the maximum iteration number (generations) and iter is the current iteration number. A particle goes to a direction computed from the best visited position and the best visited position of all particles in its neighborhood. The original PSO algorithm is directly applicable to the problems with continuous domain with no constraints. Therefore, we need to carefully revise the original PSO to consider the equality/inequality constraints of the variables in the process of each individual's search for the EED problem.

\subsection{Implementation of PSO algorithm in EED/MEED problem}

This study presents an optimal solution to different types of EED/MEED problems using the PSO algorithm. Its implementation consists of the following steps: 
Step 1. Set the parameter of units, power demand, and initialize the power balance penalty factor $(p f)$

Step 2. In the EED problems the number of on-line generating problems is the dimension of this stage. The particles are randomly generated between the maximum and the minimum operating limits of the units. For example, if there are $n$ units, the ith particle is represented as follows:

$$
P_{G i}=\left[P_{i 1}, P_{i 2}, \ldots, P_{i d}\right], \quad i=1,2, \ldots, n
$$

In the MEED problems, each particle would be extended to the $C_{2}^{m}$ combination dimensions of power transfer variable $\left(P_{T i}\right)$ between areas. Then the population of individuals is extended as:

$$
P_{m i}=\left[P_{G i}, P_{T i}\right], \quad i=1,2, \ldots, n
$$

Step 3. Calculate $h$ (the price penalty factor; $h_{m}$ for MEED) using the six-step procedure based on (5) to (7).

Step 4. Evaluate the fitness of each individual $P_{G i}\left(P_{m i}\right.$ for MEED) in the population as follows: For EED problem:

$$
\text { Fitness }=\text { Eq. }(1)+p f \cdot[\text { Eq. }(2)]
$$

For MEED problem:

$$
\text { Fitness }=\text { Eq. }(8)+p f \cdot[\text { Eq. }(9)] \text {, }
$$

where the power balance penalty factor $(p f)$ introduces the equation of constraint to converge to zero in brackets in the fitness function, the $p f$ is placed into the objective function in such a way that it penalizes any violation of the constraints and forces the unconstrained optimal solution towards the feasible region.

Step 5. If the stopping criteria are met, then go to Step 9, Otherwise, go to step 6

Step 6. The best value among the all $P_{\text {best }}$ value, $G_{\text {best }}$, is identified. The objective function values are calculated for the updated position of particles. If the new value is better than the previous $P_{\text {best }}$, the new value is set to $P_{\text {best }}$.

Step 7. New velocities for all the dimensions in each particle are calculated using Eq. (12). The position of each particle is updated using Eq. (13).

Step 8. Check the variables of each individual and adjust to max/min bound for exceed/less than the limit bound of Equ. (3) [Eq. (10), (11) for MEED]. Go to Step 4.

Step 9. If Eq. (2) [Eq. (9) for MEED] is less than $\varepsilon\left(\varepsilon=1 \times 10^{-5}\right)$, the positions of particles represented by $G_{b e s t}$ are the optimal solution, and stop. Otherwise, $p f=p f+1$ and the procedure is repeated form Step 4. 
Fig. 1 shows the flowchart of the EED/MEED problems optimization for the proposed PSO.

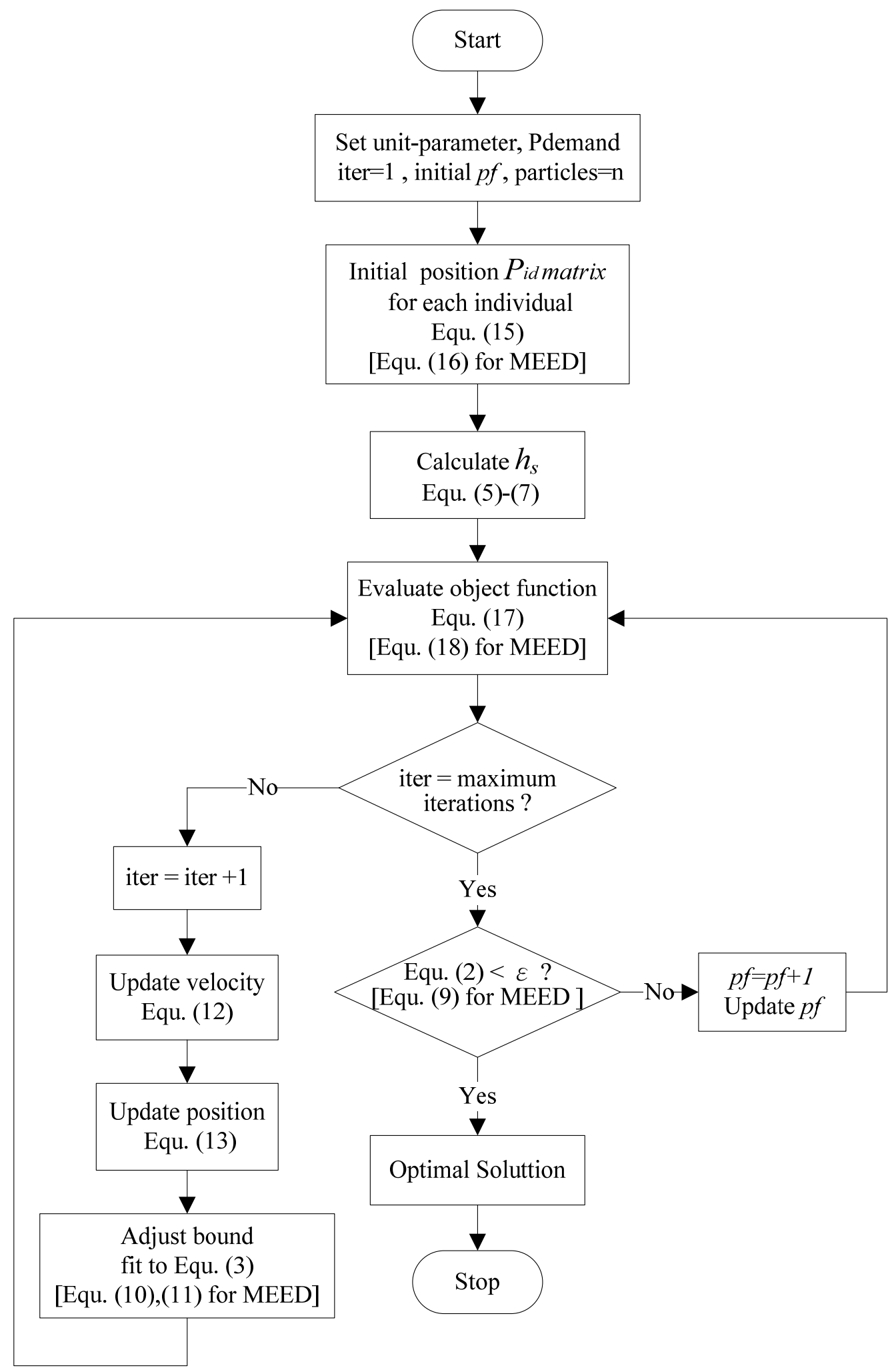

Fig 1. The flow process of proposed PSO for EED/MEED 


\section{Implementation of the Proposed Approach}

In this section, we explain the experimental results for the implementation of our proposed PSO method for three different types of economic dispatch problems namely, (1) standard IEEE 30-bus test; (2) comparison approaches for EED and (3) multi-area EED. For all three types of problems, the proposed PSO method was solved using MATLAB 7.0 platform with P4, 1.5 GHz.

\subsection{Standard IEEE 30-bus test}

The IEEE 30-bus system with 6 generators is presented here where the power demand was 700 MW. The fuel cost, $\mathrm{NO}_{\mathrm{x}}$ emission coefficients, and loss coefficients are given in Table 1 and $B_{m \times n}$. In the simulations, for the power demand of $700 \mathrm{MW}$, after some trials, the population size and the price penalty factor were set to 100 and 44.788, respectively and the minimum of fuel cost and $\mathrm{NO}_{\mathrm{x}}$ emission were obtained, successfully (Fig. 2). At the same time, convergence of fuel cost and the amount of $\mathrm{NO}_{\mathrm{x}}$ emission are shown in Fig. 3. The optimal results of fuel cost and emission are also reported in Table 2. The parameters of proposed PSO algorithms used are as follows,

- Population size $=100$

- Generations/Iterations $=100$

- Initial $p f=90$

- Initial weight $w$ is set by Eq. (14), where $w_{\max }=0.9$ and $w_{\min }=0.4$.

- Acceleration constant $c_{1}=1.0, c_{2}=0.7$ is set by Eq. (12)

$$
B_{m n}=\left[\begin{array}{llllll}
0.002022 & -0.000286 & -0.000534 & -0.000565 & -0.000454 & -0.000103 \\
-0.000286 & 0.003243 & 0.000016 & -0.000307 & -0.000422 & -0.000147 \\
-0.000533 & 0.000016 & 0.002085 & 0.000831 & 0.000023 & -0.00027 \\
-0.000565 & -0.000307 & 0.000831 & 0.001129 & 0.000113 & -0.000295 \\
-0.000454 & -0.000422 & 0.000023 & 0.000113 & 0.00046 & -0.000153 \\
0.000103 & -0.000147 & -0.00027 & -0.000295 & 0.000153 & 0.000898
\end{array}\right]
$$

\section{Table 1}

The six generators of standard IEEE 30-bus test problem

\begin{tabular}{lllllll}
\hline Unit & \multicolumn{5}{l}{ Fuel Coefficients } & \multicolumn{5}{l}{ Emission Coefficients } \\
\cline { 2 - 7 }$i$ & $\mathrm{a}$ & $\mathrm{b}$ & $\mathrm{c}$ & $\alpha$ & $\mathrm{B}$ & $\gamma$ \\
\hline 1 & 0.15247 & 38.539 & 756.79 & 0.00419 & 0.32767 & 13.859 \\
2 & 0.10587 & 46.159 & 451.32 & 0.00419 & 0.32767 & 13.859 \\
3 & 0.02803 & 40.396 & 1049.99 & 0.00683 & -0.54551 & 40.266 \\
4 & 0.03546 & 38.305 & 1243.53 & 0.00683 & -0.54551 & 40.266 \\
5 & 0.02111 & 36.327 & 1658.56 & 0.00461 & -0.51116 & 42.895 \\
6 & 0.01799 & 38.270 & 1356.65 & 0.00461 & -0.51116 & 42.895 \\
\hline
\end{tabular}




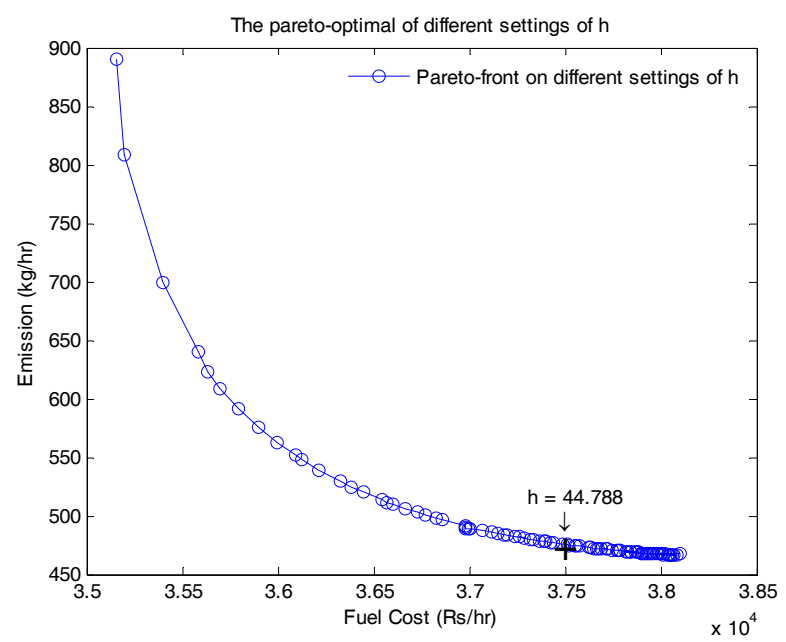

Fig 2. PSO algorithms with different settings of price penalty factors

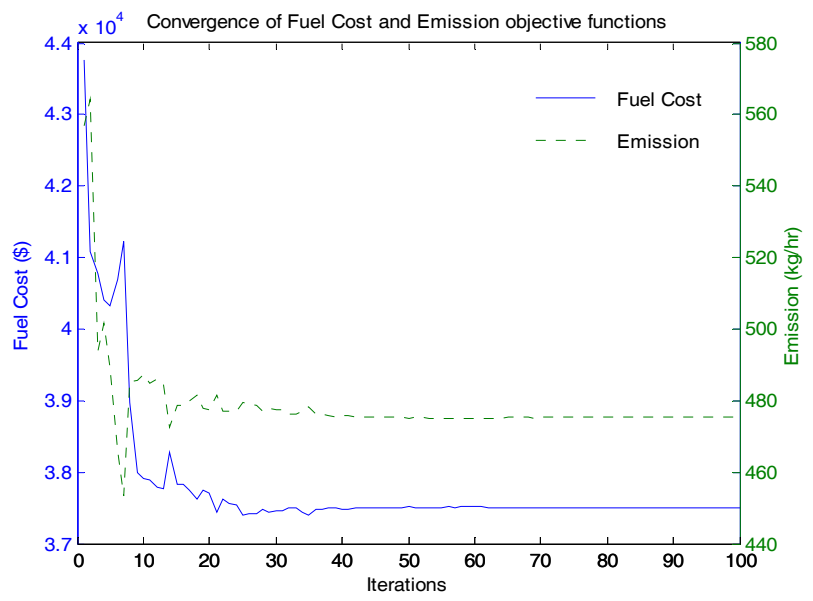

Fig. 3. Convergence of fuel cost and emission objective functions

\section{Table 2}

Test results obtained from the six generators of standard IEEE 30-bus system

\begin{tabular}{|c|c|c|c|c|c|c|c|}
\hline \multirow{2}{*}{$\begin{array}{c}\text { Unit } \\
i\end{array}$} & \multicolumn{2}{|c|}{$\begin{array}{l}\text { Capacity } \\
\text { Limits }\end{array}$} & \multirow{2}{*}{$\begin{array}{l}\text { Economic } \\
\text { Dispatch }\end{array}$} & \multirow{2}{*}{$\begin{array}{c}\text { Fuel } \\
\text { Cost(Rs/hr) }\end{array}$} & \multirow[t]{2}{*}{ Emission( $\mathrm{kg} / \mathrm{hr})$} & \multirow[t]{2}{*}{$\begin{array}{l}\text { Emission cost } \\
\quad(\mathrm{Rs} / \mathrm{hr})\end{array}$} & \multirow[t]{2}{*}{$\begin{array}{l}\text { Total operation cost } \\
\text { (Rs/hr) }\end{array}$} \\
\hline & $P_{i}^{\max }$ & $P_{i}^{\min }$ & & & & & \\
\hline 1 & 10 & 125 & 72.5 & 4352.3 & 59.6 & 2668.9 & 7021 \\
\hline 2 & 10 & 150 & 43.8 & 2676.2 & 36.2 & 1621.0 & 4297 \\
\hline 3 & 35 & 225 & 79.5 & 4438.7 & 40.1 & 1795.7 & 6234 \\
\hline 4 & 35 & 210 & 104.8 & 5647.4 & 58.1 & 2601.7 & 8249 \\
\hline 5 & 130 & 325 & 233.8 & 11305.9 & 175.3 & 7849.9 & 19156 \\
\hline 6 & 125 & 315 & 185.2 & 9061.4 & 106.3 & 4760.1 & 13821 \\
\hline \multicolumn{3}{|c|}{ Amount } & 719.6 & 37482.0 & 475.6 & 21297.4 & 58779 \\
\hline \multicolumn{4}{|c|}{$\begin{array}{l}\text { Power Demand } \\
\text { Power Loss }\end{array}$} & $\begin{array}{l}700 \mathrm{MW} \\
19.6 \mathrm{MW}\end{array}$ & & & \\
\hline
\end{tabular}




\subsection{Comparison approaches for EED}

The proposed PSO method of this paper was also applied on a system consists of three thermal units in order to investigate its effectiveness. For comparison purposes with the reported results, the system is considered as a three units test system whose data are given in Table 3 and the loss coefficient matrix $\left(B_{m n}\right)$ are as follows,

$$
B_{m n}=\left[\begin{array}{ccc}
0.000071 & 0.00003 & 0.000025 \\
0.00003 & 0.000069 & 0.000032 \\
0.000025 & 0.000032 & 0.00008
\end{array}\right]
$$

Table 3

The system tested consists of three thermal units

\begin{tabular}{ccccccccc}
\hline Unit & $P_{i}^{\max }$ & $P_{i}^{\min }$ & \multicolumn{3}{c}{ Fuel Coefficients } & \multicolumn{3}{c}{ Emission Coefficients } \\
\cline { 5 - 8 }$i$ & $(\mathrm{MW})$ & $(\mathrm{MW})$ & $\mathrm{a}$ & $\mathrm{b}$ & $\mathrm{c}$ & $\alpha$ & $\mathrm{B}$ & $\gamma$ \\
\hline 1 & 35 & 210 & 0.03546 & 38.305 & 1243.53 & 0.00683 & -0.545 & 40.266 \\
2 & 130 & 325 & 0.02111 & 36.327 & 1658.56 & 0.00461 & -0.511 & 42.895 \\
3 & 125 & 315 & 0.01799 & 38.270 & 1356.65 & 0.00461 & -0.511 & 42.895 \\
\hline
\end{tabular}

The results of the proposed PSO approach were compared to those reported using conventional lambda iterative method and Genetic algorithm (Sudhakaran et al. 2004). Table 4 lists the parameters of GA and PSO approach.

Table 4

The parameters of GA and PSO approach

\begin{tabular}{|c|c|}
\hline Approach & Set parameters \\
\hline GA & $\begin{array}{l}\cdot \text { Population size }=20 \\
\cdot \text { Number of iterations }=100 \\
\cdot \text { Probability of crossover } 0.6-0.7 \\
\cdot \text { Probability of mutation } 0.001-0.1\end{array}$ \\
\hline PSO & $\begin{array}{l}\text { - } \text { Population size }=40 \\
\text { - Generations/Iterations }=50 \\
\text { - Initial } p f=70 \\
\text { - Initial weight } w \text { is set by Eq. (14), where } w_{\max }=0.9 \text { and } w_{\min }=0.4 \text {. } \\
\text { - Acceleration constant } c_{1}=1.0, c_{2}=0.7 \text { is set by Eq. (12). }\end{array}$ \\
\hline
\end{tabular}

The results for the best fuel cost for the power demands of $400 \mathrm{MW}, 500 \mathrm{MW}$ and $700 \mathrm{MW}$ are presented in Table 5. The results obtained from PSO are then compared with conventional lambda iterative method and GA. From the results it is clear that PSO gives minimum fuel cost and minimum $\mathrm{NO}_{\mathrm{x}}$ Emission. Since the conventional method depends on the exact adjustment of lambda value it cannot give the accurate solution for the EED problem. As compared to GA, the advantages of PSO are that PSO is easier to implement and there are fewer parameters to adjust. In Fig. 4, we have depicted the convergence rate of the PSO along with the number of iterations. 
Table 5

Comparison of test results obtained from conventional method, GA and PSO

\begin{tabular}{lllllllll}
\hline $\begin{array}{l}P_{\text {demnad }} \\
(\mathrm{MW})\end{array}$ & Method & $\begin{array}{l}P_{1} \\
(\mathrm{MW})\end{array}$ & $\begin{array}{l}\mathrm{P}_{2} \\
(\mathrm{MW})\end{array}$ & $\begin{array}{l}\mathrm{P}_{3} \\
(\mathrm{MW})\end{array}$ & $\begin{array}{l}\mathrm{P}_{4} \\
(\mathrm{MW})\end{array}$ & $\begin{array}{l}\text { Fuel Cost } \\
(\mathrm{Rs} / \mathrm{h})\end{array}$ & $\begin{array}{l}\text { Emission } \\
(\mathrm{kg} / \mathrm{h})\end{array}$ & $\begin{array}{l}\text { Total } \\
\text { Operation } \\
\text { Cost(Rs/hr) }\end{array}$ \\
\hline \multirow{4}{*}{400} & Conv. & 102.7 & 153.9 & 151.1 & 7.4 & 20,849 & 201.5 & 29,830 \\
& GA & 99.5 & 147.3 & 161.9 & 7.7 & 20,858 & 201.3 & 29,874 \\
& PSO & 102.6 & 153.7 & 151.2 & 7.4 & 20,838 & 200.2 & 29,809 \\
\hline \multirow{4}{*}{500} & Conv. & 120.0 & 192.8 & 190.1 & 11.9 & 25,079 & 312.0 & 39,458 \\
& GA & 127.5 & 200.6 & 183.4 & 11.8 & 25,482 & 311.9 & 39,448 \\
& PSO & 128.8 & 192.6 & 190.3 & 11.7 & 25,494 & 311.2 & 39,430 \\
\hline \multirow{4}{*}{700} & Conv. & 182.6 & 271.3 & 269.5 & 23.4 & 35,463 & 652.6 & 66,690 \\
& GA & 190.1 & 274.7 & 258.2 & 23.3 & 35,476 & 652.0 & 66,659 \\
\hline
\end{tabular}

For the various power demands, all the approaches are applied and the solutions obtained are compared in Fig. 5. From the results it is clear that PSO gives minimum fuel cost and minimum $\mathrm{NO}_{\mathrm{x}}$ emission as compared to conventional lambda iterative method and GA method. The PSO approach has also demonstrated an ability to provide accurate and feasible solutions for the EED within reasonable computation resource.



(a)

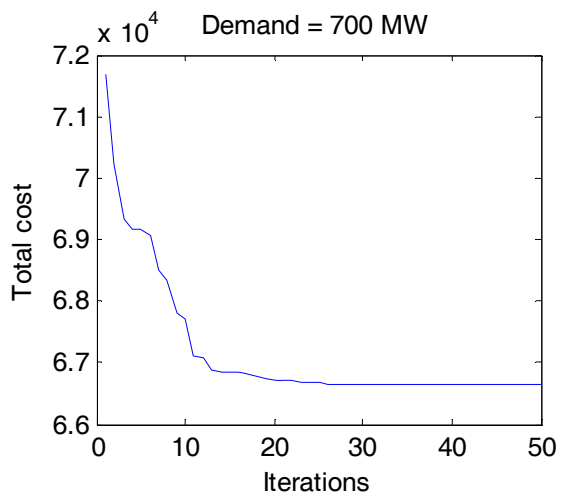

(c)

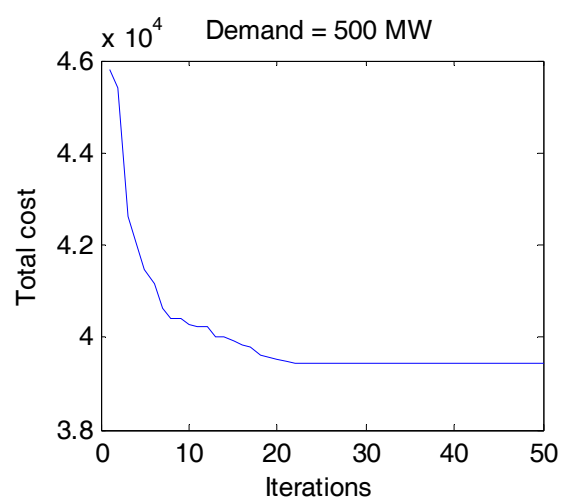

(b)

Fig. 4 The convergence nature of PSO for various demands

(a) Power demand $=400 \mathrm{MW}$ Total operation $\operatorname{cost}=29,809 \mathrm{Rs} / \mathrm{hr}$

(b) Power demand $=500 \mathrm{MW}$ Total operation $\operatorname{cost}=39,430 \mathrm{Rs} / \mathrm{hr}$

(c) Power demand $=700 \mathrm{MW}$

Total operation $\operatorname{cost}=66,624 \mathrm{Rs} / \mathrm{hr}$ 


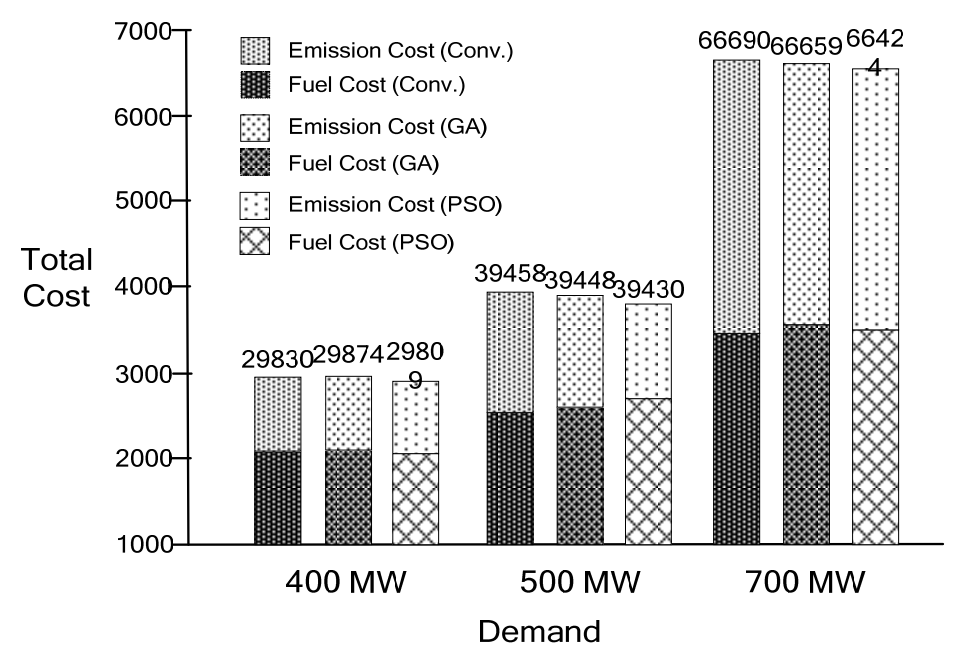

Fig 5. The test results obtained from comparison approached for various power demands

\subsection{Multi-area EED}

We have also used the proposed PSO algorithm to deal with the MEED problem and in our study, a four-area test system interconnected by six tie lines. There are three generators in each area with different fuel, emission and transmission loss characteristics shown in Table 6 and Table 7, respectively. One important issue is to consider the tie line capacity between power plants in multiarea systems in MEED analysis which results a suitable index to site new power plants or to invest on transmission system in capacity constrained systems. In this research, a distributed system with more buses and lines is considered which are divided in four areas and they are connected together. A portion of the total load exists in each area; a portion of this area's load is generated in it and what is left in area's load demand is fed and supported by other areas and the loss are given in Table 8 . The power demand of $1^{\text {st }} \sim 4^{\text {th }}$ area are $500,410,580$ and $600 \mathrm{MW}$, respectively. The parameters of proposed PSO algorithms used are as follows,

- Population size $=500$

- Generations/Iterations $=100$

- Initial $p f=120$

- Initial weight $w$ is set by Eq. (14), where $w_{\max }=0.9$ and $w_{\min }=0.4$.

- Acceleration constant $c_{1}=1.0, c_{2}=0.7$ is set by Eq. (12).

Table 6

Data for the multiarea generators test problem

\begin{tabular}{|c|c|c|c|c|c|c|c|c|c|}
\hline \multirow{2}{*}{ Area } & \multirow{2}{*}{$\begin{array}{c}\text { Unit } \\
i\end{array}$} & \multirow{2}{*}{$\begin{array}{l}P_{i}^{\operatorname{Max}} \\
(\mathrm{MW})\end{array}$} & \multirow{2}{*}{$\begin{array}{c}P_{i}^{\text {Min }} \\
\text { (MW) }\end{array}$} & \multicolumn{3}{|c|}{ Fuel Coefficients } & \multicolumn{3}{|c|}{ Emission Coefficients } \\
\hline & & & & $\mathrm{a}$ & $\mathrm{b}$ & $\mathrm{c}$ & $\alpha$ & $\beta$ & $\gamma$ \\
\hline \multirow{3}{*}{1} & 1 & 35 & 210 & 0.03546 & 38.30553 & 1243.5311 & 0.00683 & -0.54551 & 40.2669 \\
\hline & 2 & 130 & 325 & 0.02111 & 36.32782 & 1658.5696 & 0.00461 & -0.5116 & 42.89553 \\
\hline & 3 & 125 & 315 & 0.01799 & 38.27041 & 1356.6592 & 0.00461 & -0.5116 & 42.89553 \\
\hline \multirow{3}{*}{2} & 1 & 10 & 150 & 0.15247 & 38.53973 & 756.7989 & 0.00484 & -0.32767 & 33.85932 \\
\hline & 2 & 35 & 110 & 0.02803 & 40.39655 & 449.9977 & 0.00754 & -0.54551 & 50.63931 \\
\hline & 3 & 125 & 215 & 0.14834 & 38.34001 & 558.5696 & 0.00661 & -0.63262 & 45.83267 \\
\hline \multirow{3}{*}{3} & 1 & 15 & 175 & 0.10587 & 46.15916 & 451.3251 & 0.00914 & -0.43211 & 48.2156 \\
\hline & 2 & 30 & 215 & 0.07505 & 43.83562 & 673.0267 & 0.00533 & -0.61173 & 52.4521 \\
\hline & 3 & 50 & 335 & 0.11934 & 50.63211 & 530.7199 & 0.00674 & -0.49731 & 41.1042 \\
\hline \multirow{3}{*}{4} & 1 & 15 & 175 & 0.10587 & 46.15916 & 851.3251 & 0.00728 & -0.6821 & 30.3632 \\
\hline & 2 & 30 & 215 & 0.13552 & 41.03782 & 1038.533 & 0.00479 & -0.5066 & 25.1765 \\
\hline & 3 & 50 & 335 & 0.08963 & 33.56211 & 1285.907 & 0.00387 & -0.4934 & 27.7549 \\
\hline
\end{tabular}


Table 7

The $B_{m n}$ matrix of the loss coefficients of all area

$$
\begin{aligned}
& B_{m n}^{\text {Area }-1}=\left[\begin{array}{ccc}
0.000071 & 0.00003 & 0.000025 \\
0.00003 & 0.000069 & 0.000032 \\
0.000025 & 0.000032 & 0.00008
\end{array}\right] \quad B_{m n}^{\text {Area }-2}=\left[\begin{array}{ccc}
0.000056 & 0.000045 & 0.000015 \\
0.000023 & 0.000042 & 0.000047 \\
0.000032 & 0.000023 & 0.000027
\end{array}\right] \\
& B_{m n}^{\text {Area }-3}=\left[\begin{array}{ccc}
0.00002 & 0.000028 & 0.000053 \\
0.000086 & 0.000034 & 0.000016 \\
0.000053 & 0.000016 & 0.000028
\end{array}\right] \quad B_{m n}^{\text {Area }-4}=\left[\begin{array}{ccc}
0.000074 & 0.00003 & 0.000025 \\
0.000049 & 0.000069 & 0.000037 \\
0.000022 & 0.000032 & 0.000083
\end{array}\right]
\end{aligned}
$$

Table 8

\begin{tabular}{|c|c|c|c|c|}
\hline \multicolumn{2}{|c|}{ Area } & \multicolumn{2}{|c|}{ Tie Line Capacity } & \multirow{2}{*}{$\begin{array}{c}\text { Tie Line } \\
\text { Transfer Loss } \\
\left(\rho_{\mathrm{km}}\right)\end{array}$} \\
\hline From & To & $T_{k m, \min }$ & $T_{k m, \max }$ & \\
\hline 1 & 2 & 5 & 60 & $13 \%$ \\
\hline 1 & 3 & 5 & 50 & $19 \%$ \\
\hline 1 & 4 & 5 & 60 & $14 \%$ \\
\hline 2 & 1 & 5 & 60 & $11 \%$ \\
\hline 2 & 3 & 5 & 60 & $12 \%$ \\
\hline 2 & 4 & 5 & 50 & $20 \%$ \\
\hline 3 & 1 & 5 & 50 & $21 \%$ \\
\hline 3 & 2 & 5 & 60 & $14 \%$ \\
\hline 3 & 4 & 5 & 60 & $13 \%$ \\
\hline 4 & 1 & 5 & 60 & $16 \%$ \\
\hline 4 & 2 & 5 & 50 & $22 \%$ \\
\hline 4 & 3 & 5 & 60 & $11 \%$ \\
\hline
\end{tabular}

The flow limits and the percentage of transfer loss on the tie lines

From the simulation results, it is evident that both fuel costs and emissions of the MEED with interarea aid perform better than the separate areas without inter-area aid case. The minimum fuel costs and the minimum emissions obtained with and without inter-area aid are shown in Table 9 and Table 10 , respectively. Thus, it is desirable to connect the multiple areas for achieving lower fuel costs and emissions while satisfying the power demands of different areas. Based on the above simulation results, we can also find that except for area 3, other three areas are all capable of satisfying the allowable emission limit (e.g. $E_{\text {limit }}=500 \mathrm{~kg}$ 's) by themselves. Only area 3 needs emission controlled (EC) economic dispatch sharing from other area in order to cover the additional power for emission limit satisfaction.

Table 9

Minimum Fuel costs and Emission without Inter-area Aid

\begin{tabular}{ccccccccc}
\hline Area & $\begin{array}{c}P_{1} \\
(\mathrm{MW})\end{array}$ & $\begin{array}{c}P_{2} \\
(\mathrm{MW})\end{array}$ & $\begin{array}{c}P_{3} \\
(\mathrm{MW})\end{array}$ & $\begin{array}{c}P_{\text {los }} \\
(\mathrm{MW})\end{array}$ & $\begin{array}{c}\text { Fuel Cost } \\
(\mathrm{Rs} / \mathrm{h})\end{array}$ & $\begin{array}{c}\text { Emission } \\
(\mathrm{kg} / \mathrm{h})\end{array}$ & $h_{m}$ & $\begin{array}{c}\text { Total } \\
\text { Operation } \\
\text { Cost }(\mathrm{Rs} / \mathrm{hr})\end{array}$ \\
\hline 1 & 128.87 & 192.54 & 190.28 & 11.69 & 25494.7 & 311.15 & 44.81 & 39436.2 \\
2 & 147.90 & 132.02 & 136.07 & 5.99 & 24585.7 & 283.44 & 106.49 & 54769.0 \\
3 & 166.52 & 215 & 211.11 & 12.63 & 41179.0 & 633.52 & 81.09 & 92550.6 \\
4 & 155.19 & 201.32 & 261.77 & 18.28 & 41570.6 & 380.95 & 117.13 & 86191.5 \\
\hline Total & & & & 48.59 & 132830.0 & 1609.06 & & 272947.3 \\
\hline
\end{tabular}


Table 10

Minimum Fuel costs and Emission with Inter-area Aid

\begin{tabular}{ccccccccc}
\hline Area & $\begin{array}{c}P_{1} \\
(\mathrm{MW})\end{array}$ & $\begin{array}{c}P_{2} \\
(\mathrm{MW})\end{array}$ & $\begin{array}{c}P_{3} \\
(\mathrm{MW})\end{array}$ & $\begin{array}{c}P_{\text {los }} \\
(\mathrm{MW})\end{array}$ & $\begin{array}{c}\text { Fuel Cost } \\
(\mathrm{Rs} / \mathrm{h})\end{array}$ & $\begin{array}{c}\text { Emission } \\
(\mathrm{kg} / \mathrm{h})\end{array}$ & $h_{m}$ & $\begin{array}{c}\text { Total } \\
\text { Operation } \\
\text { Cost }(\mathrm{Rs} / \mathrm{hr})\end{array}$ \\
\hline 1 & 168.1 & 165.3 & 256.6 & 15.69 & 29282.8 & 440.9 & 44.81 & 49038.5 \\
2 & 140.4 & 100.3 & 175.2 & 5.70 & 25780.4 & 292.9 & 106.49 & 56965.6 \\
3 & 147.8 & 214.6 & 201.5 & 11.30 & 38702.4 & 565.2 & 81.09 & 84536.3 \\
4 & 129.3 & 164.8 & 290.3 & 16.85 & 38651.3 & 346.3 & 117.13 & 79207.1 \\
\hline Total & & & & 49.54 & 132416.9 & 1645.2 & & 269747.4 \\
\hline
\end{tabular}

The MEED problem will become more complicated when the impact of emissions controlled must be considered since the MEED problem must be added to the emission constraint as follows,

$$
\sum_{i=1}^{n}\left(\alpha_{m i} p_{m i}^{2}+\beta_{m i} p_{m i}+\gamma_{m i}\right) \leq E_{\text {limit }} \text {. }
$$

Table 11 illustrates the emission controlled for the MEED problem. From the results, we can see that when the area emission controlled limits requirements are considered, higher operation cost are inevitably caused for achieving MEED system economic dispatch. The tie-line transfers between areas with/without emission controlled are shown in Table 12. Fig. 6 shows a comparison between the total cost of MEED with and without emission controlled.

Table 11

The results of emission controlled for MEED $\left(E_{\text {limit }}=500 \mathrm{~kg} / \mathrm{hr}\right.$ for each area $)$

\begin{tabular}{ccccc}
\hline Area & Fuel Cost & Emission & Emission Cost & $\begin{array}{c}\text { Total Operation } \\
\text { Cost (Rs/hr) }\end{array}$ \\
\hline 1 & 30371.8 & 486.3 & 21787.5 & 52159.2 \\
2 & 26015.7 & 303.7 & 32337.4 & 58353.1 \\
3 & 35986.6 & 500.0 & 40533.0 & 76519.5 \\
4 & 39671.0 & 370.9 & 43444.6 & 83115.5 \\
\hline Total & 132045.0 & 1660.8 & 138102.4 & 270147.5 \\
\hline
\end{tabular}

Table 12

The tie-line transfer between areas with/without emission controlled ( $E_{\text {limit }}=500 \mathrm{~kg} / \mathrm{hr}$ for each area)

\begin{tabular}{|c|c|c|c|}
\hline \multicolumn{2}{|c|}{ Area } & Without & With \\
\hline From & To & Controlled & $\begin{array}{l}\text { Emission } \\
\text { Controlled }\end{array}$ \\
\hline 1 & 2 & 33.4 & 0 \\
\hline 1 & 3 & 8.9198 & 46.003 \\
\hline 1 & 4 & 31.912 & 49.521 \\
\hline 2 & 3 & 22.902 & 0 \\
\hline 2 & 4 & 6.3079 & 0 \\
\hline 4 & 3 & 0 & 22.96 \\
\hline
\end{tabular}




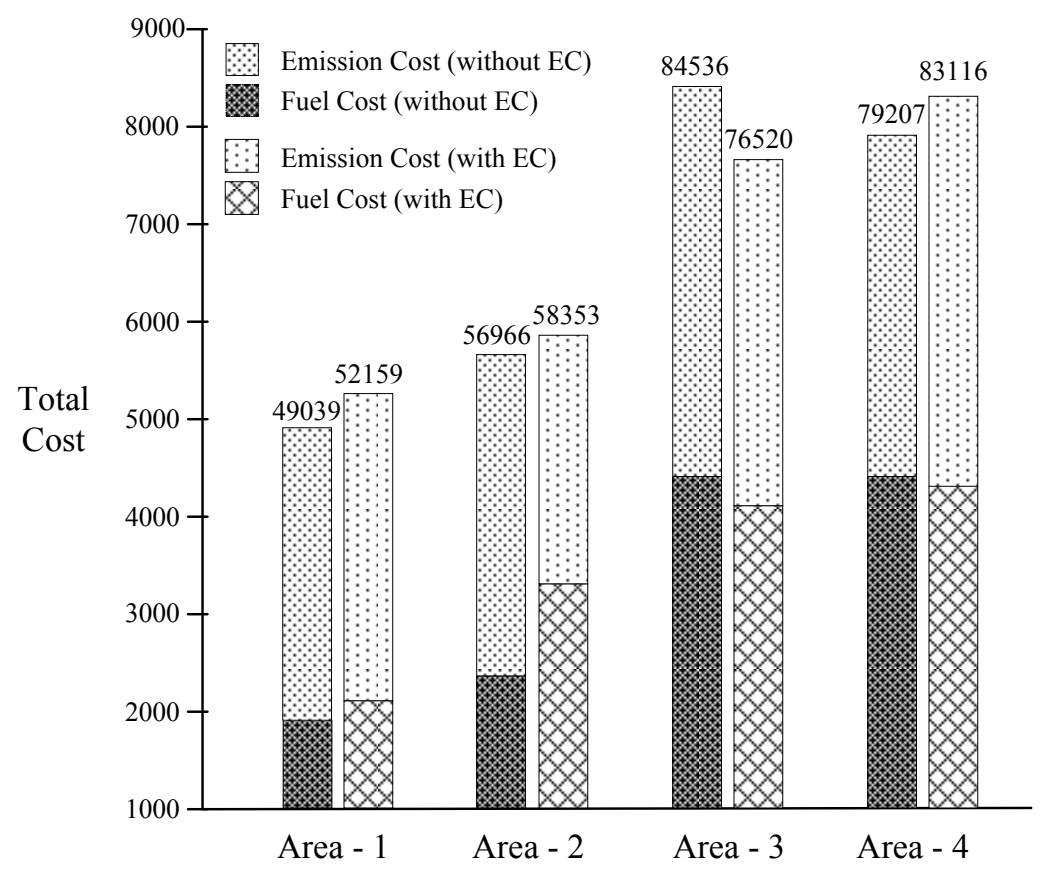

Fig 6. Total cost of MEED with/without emission controlled $\left(E_{\text {limit }}=500 \mathrm{~kg} / \mathrm{hr}\right.$ for each area)

From the aforementioned simulation results, it is evident that both fuel costs and emissions of the MEED with inter-area aid dominate those of the separate areas case. Thus, it is desirable to connect the multiple areas for achieving lower fuel costs and emissions while satisfying the power demands and allowable emission limits of different areas.

\section{CONCLUSIONS}

The traditional economic dispatch (ED) has only one objective for minimizing fuel costs. With the increasing awareness of environmental protection in recent years, environmental/economic dispatch (EED) is proposed as an alternative to achieve the minimization of fuel costs and pollutant emissions, simultaneously. At the same time, we have further extended the concept of EED into the new concept termed multi-area environmental/economic dispatch (MEED) which was proposed by also minimizing the pollutant emissions in the emission controlled context. The application of the PSO algorithms to different types of ED problems has been demonstrated in this paper. The test results for the EED/MEED typical problems indicate that the proposed PSO works relatively better than the other mentioned methods. The better computation efficiency and convergence property of the proposed PSO algorithms show that it could be applied to a wide range of optimization problems. As a future work, the applications can be considered to further increase the system security. Other issues such as emission quota trade, transmission costs, and buying and selling policies between areas can also be considered to reflect more realistic situations in MEED problems.

\section{Acknowledgment}

The authors would like to thank the anonymous referees for their constructive comments on earlier version of this work. 


\section{References}

Palanichamy, C. \& Srikrishna, K. (1991). Economic thermal power dispatch with emission constraint. Journal of Institution of Engineers, 72, 11-18.

Dhillon, J. S., Parti, S. C. \& Kothari, D. P. (1993). Stochastic economic emission load dispatch, Electric Power Systems Research, 26, 179-186.

Talaq, J. H., El-Hawary, F. \& El-Hawary, M. E. (1994). A summary of environmental/economic dispatch algorithms, IEEE Transactions on Power Systems, 9(3), 1508-1516.

Farag, A., Al-Baiyat, S. \& T. C. Cheng, (1995). Economic load dispatch multiobjective optimization procedures using linear programming techniques, IEEE Transaction on Power System, 10, 731738.

Dhillon, J. S., Parti, S. C. \& Kothari, D. P. (1993). Stochastic economic emission load dispatch, Electric Power System Resource, 26, 186-197.

Chang, C. S., Wong, K. P. \& Fan, B. (1995). Security-Constrained multiobjective generation dispatch using bicriterion global optimization, IEE Proceedings - Generation Transmission and Distribution, 142(4), 406-414.

Abido, M. A. (2003). Enviromental/economic power dispatch using multiobjective evolutionary algorithms, IEEE Transaction on Power System, 18(4), 1529-1537.

Sudhakaran, M. \& Slochanal, S. M. (2004). Application of Refined Genetic Algorithm to Combined Economic and Emission Dispatch, Journal of the Institution of Engineer (EL), 85.

Yalcinoz, T. \& Altun, H. (2005). A new genetic algorithm with arithmetic crossover to economic and environmental economic dispatch, Engineering International System, 3, 173-180.

Wang, L. F. \& Singh, C. (2006). Multi-objective stochastic power dispatch through a modified particle swarm optimization algorithm, Special Session on Applications of Swarm Intelligence to Power Systems, Proceedings of IEEE Swarm Intelligence Symposium, 127-135.

Dhillon, J. S., Parti, S. C. \& Kothari, D. P. (2002). Fuzzy decision-making in stochastic multiobjective short-term hydrothermal scheduling, IEE Proceedings - Generation Transmission and Distribution, 149(2), 191-200.

Huang, C. M. \& Huang, Y. C. (2003). A Novel Approach to Real-Time Economic Emission Power Dispatch, IEEE Transaction on Power System, 18(1), 288-294.

Kennedy, J. \& Eberhart, R. C. Swarm intelligence, San Francisco: Morgan Kaufmann Publisher, 2001.

Kennedy, J. \& Eberhart, R. C. (1995). Particle swarm optimization, Proceeding of International Conference on Neural Networks, 4, 1942-1948.

Shi, Y. H. \& Eberhart, R. C. (1998). A Modified Particle Swarm Optimizer, IEEE International Conference on Evolutionary Computation, Anchorage, 69-73, Alaska, May 4-9.

Abido, M. A. (2002). Optimal design of power-system stabilizers using particle swarm optimization, IEEE Transactions on Energy Conversion, 17(3), 406-413. 